\title{
PERSPEKTIF PERAWAT TENTANG PENGGUNAAN TEKNOLOGI ROBOT DALAM PERAWATANPASIEN DI RUANG PERAWATAN INTENSIF
}

\author{
Suhartini Ismail ${ }^{*}$, Ragil Titi Hapsari ${ }^{2}$ \\ ${ }^{1}$ Departemen Ilmu Keperawatan, Divisi Keperawatan Gawat Darurat dan Kritis, \\ Fakultas Kedokteran Universitas Diponegoro, \\ ${ }^{2}$ Mahasiswa Program Studi Ilmu Keperawatan Fakultas Kedokteran Universitas \\ *koresponden: suhartini.ismail@fk.undip.ac.id
}

\begin{abstract}
Abstrak
Perkembangan teknologi yang begitu pesat menghasilkan berbagai inovasi canggih salah satunya teknologi robot yang digunakan untuk membantu dalam perawatan pasien di ruang Ruang perawatan intensif. Penelitian ini bertujuan untuk mendeskripsikan perspektif perawat dalam penggunaan teknologi robot dalam perawatan pasien di ruang ruang perawatan intensif. Penelitian ini merupakan penelitian kualitatif deskriptif. Partisipan penelitian sebanyak 10 perawat ruang perawatan intensif yang ditentukan dengan metode purposive sampling. Pengumpulan data dilakukan melalui wawancara sesuai dengan pedoman wawancara yang telah dipersiapkan. Data yang terkumpul dianalisa menggunakan metode Elo dan Kyngas. Hasil penelitian menghasilkan 3 tema yaitu efek positif penggunaan teknologi robot di ruang ruang perawatan intensif diantaranya teknologi robot membantu pekerjaan perawat, membantu dalam perawatan pasien dan bekerja sesuai dengan program, kemudian efek negatif penggunaan teknologi robot di ruang ruang perawatan intensif diantaranya caring perawat ke pasien berkurang, menimbulkan kecemasan pada pasien dan pengoperasian yang menjadi kendala. Kebutuhan perawat terkait pengoperasian teknologi robot di ruang ruang perawatan intensif. Penggunaan teknologi robot dalam perawatan pasien memberikan efek positif dan negatif. Penggunaan robot lebih dipentingkan untuk memaksimalkan peran perawat dalam memberikan perawatan pada pasien.
\end{abstract}

Kata kunci: Ruang perawatan intensif, perspektif perawat, teknologi, robot

\begin{abstract}
The rapid development of technology resulted in various advanced innovations, one of which is robot technology used to assist in the care of patients in the Ruang perawatan intensif room. This study aims to describe nurses' perspectives on using robot technology for patient care in the ruang perawatan intensif room. This research is descriptive qualitative research. The study participants were ten ruang perawatan intensif nurses determined by purposive sampling method. Data collection is conducted through interviews following the interview guidelines that have been prepared. The collected data is analyzed using the Elo and Kyngas methods. The study results produced three themes: the positive effect of robot technology use in the ruang perawatan intensif room, including robot technology to help nurse work, help patient care, and work according to the program. The negative effect of using robot technology in the ruang perawatan intensif room among them caring nurses to patients is reduced, causing anxiety in patients and operations that become obstacles. The nurses need related knowledge and skill related to robot technology operation in the ruang perawatan intensif room. The use of robot technology for patient care has positive and negative effects. The use of robots is more critical to maximize the role of nurses in providing care to patients.
\end{abstract}

Keywords: Intensive care unit, nurse perspective, technology, robot 


\section{Pendahuluan}

Ruang perawatan intensif (ICU) merupakan ruangan yang ditujukan untuk memberikan pelayanan secara intensif kepada pasien dengan kondisi kritis (Darmayanti \& Oktamianti P, 2014). Ruangan ICU memiliki banyak peralatan medis canggih hasil pengembangan teknologi yang digunakan untuk membantu pemantauan keadaan pasien. Tidak dapat dipungkiri bahwa kurangnya tenaga kesehatan terlatih membuat pemantauan dalam perawatan sangat bergantung dengan teknologi (Shahpori et al., 2011). Perkembangan teknologi di bidang kesehatan sangat pesat, salah satu yang terus dikembangkan adalah teknologi robot. Penggunaan robot telah menyebar cepat di berbagai rumah sakit luar negeri dengan 1 juta pasien dipantau dalam kurun waktu 10 tahun terakhir. Pada studi yang telah dilakukan, terdapat hasil yang bervariasi seperti adanya perubahan yang signifikan maupun tidak terdapat perubahan signifikan pada keadaan pasien dengan penggunaan robot (Khunlertkit \& Carayon, 2013).

Pada penelitian lainnya, terdapat perbedaan antara persepsi perawat terkait adanya robot. Hasil yang didapatkan, $36 \%$ perawat mengatakan bahwa efek positifnya bertambahnya dukungan fasilitas kesehatan dan adanya peningkatan keahlian baik bagi perawat maupun dokter. Sementara itu terdapat $22 \%$ perawat mengatakan efek negatifnya adalah adanya penurunan kualitas asuhan keperawatan yang diberikan kepada pasien, terjadi penurunan interaksi dan komunikasi antara perawat dan pasien (Shahpori et al., 2011). Duni keperawatan sekarang menjadi menarik mengenai kemampuan perawat terhadap kemajuan teknologi seperti dengan adanya penggunaan robot yang membuat pekerjaan lebih efektif dan efisien. Ketika suatu saat nanti teknologi robot diterapkan dalam perawatan pasien, hal apa saja yang perlu dilakukan untuk mencapai dan mempertahankan kesehatan pasien dengan robot sebagai alat bantu cerdas (Pepito \& Locsin, 2019).

Berdasarkan studi pendahuluan dan berbagai hasil literatur terkait penelitian penggunaan robot di ruang ICU memiliki efek positif dan negatif misalnya bagi tenaga perawat adanya robot dapat mengurangi beban kerja dan efek negatifnya seperti berkurangnya interaksi dan sikap caring yang dilakukan perawat untuk pasien (Tanioka et al., 2019). Oleh karena itu peneliti melakukan sebuah penelitian kualitatif yang bertujuan untuk mengetahui perspektif perawat terkait penggunaan robot pada pasien di ruang perawatan intensif

\section{Metode}

Jenis penelitian yang digunakan adalah penelitian kualitatif diskriptif.. Teknik pengambilan sampel yang dipilih adalah nonprobability sampling dengan purposive sample. Besar sampel penelitian ini sebanyak 10 perawat ruang ICU dengan pendidikan minimal ners di rumah sakit di Kota Semarang. Pengumpulan data dilakukan melalui wawancara sesuai dengan pedoman wawancara. Data yang terkumpul dianalisa menggunakan metode Elo dan Kyngas.

\section{Hasil}

Karakteristik partisipan meliputi usia, jenis kelamin, dan lama kerja. Rentang usia partisipan antara 31-40 tahun dengan 60\%. Mayoritas partisipan berjenis kelamin lakilaki dengan $60 \%$. Kemudian lama kerja mayoritas partisipan adalah lebih dari 5 tahun dengan $80 \%$ (Tabel 1). 
Tabel 1. Distribusi Frekuensi Karakteristik Partisipan (N=10)

\begin{tabular}{llcc}
\hline No. & Karakteristik Demografi & $\begin{array}{c}\text { Frekuensi } \\
\text { (f) }\end{array}$ & Presentase (\%) \\
\hline 1. & Usia & 4 & 40 \\
& 20-30 tahun & 6 & 60 \\
& 31-40 tahun & & \\
2. Jenis Kelamin & 6 & 60 \\
& laki-laki & 4 & 40 \\
& perempuan & & \\
4. Lama Kerja & 2 & 20 \\
& 2-5 tahun & 8 & 80 \\
& $>5$ tahun & &
\end{tabular}

\section{Perspektif perawat tentang penggunaan teknologi robot dalam perawatan pasien di Ruang perawatan intensif}

Hasil penelitian ini menghasilkan tiga tema terkait perspektif perawat tentang penggunaan teknologi robot dalam perawatan pasien di ruang perawatan intensif yaitu: 1) Efek positif penggunaan teknologi robot di ruang ruang perawatan intensif, 2) Efek negatif penggunaan teknologi robot di ruang ruang perawatan intensif, 3) Kebutuhan perawat terkait pengoperasian teknologi robot di ruang ruang perawatan intensif.

\section{Tema 1: Efek positif penggunaan teknologi robot di ruang ruang perawatan intensif}

Pengaplikasian teknologi robot di ruang ruang perawatan intensif memiliki efek positif dari penggunaannya. Partisipan menjelaskan bahwa efek positif penggunaan teknologi robot yaitu dapat membantu perawat dan pasien.

Sub tema 1.1: Teknologi robot dapat membantu pekerjaan perawat

Partisipan menjelaskan bahwa pekerjaan perawat di ruang ruang perawatan intensif membutuhkan lebih banyak tenaga, ketelitian dan perhatian yang tinggi karena kondisi kesehatan pasien yang bisa berubah setiap saat. Penggunaan teknologi robot di ruang ruang perawatan intensif dapat membantu perawat sehingga pekerjaan perawat menjadi lebih ringan. Partisipan menjelaskan sebagai berikut:

“... misalnya teknologi robot untuk transfer alat atau obat-obatan pasien ruang ruang perawatan intensif, itu akan sangat membantu perawat dari segi tenaga dan waktu sehingga perawat bisa melakukan pekerjaan lain. (N7)

Sub tema 1.2: Teknologi robot bekerja sesuai dengan program

Partisipan menjelaskan bahwa kelebihan dari penggunaan teknologi robot salah satunya adalah robot bekerja sesuai dengan program yang dimiliki sehingga kemungkinan terjadi kesalahan dalam pekerjaan atau tindakan yang dilakukan semakin sedikit. Partisipan menjelaskan sebagai berikut:

"Teknologi robot yang diprogram untuk menghitung dosis obat yang diberikan kepada pasien akan sangat membantu sehingga mengurangi kesalahan dalam pemberian dosis obat kepada pasien." (N6)

\section{Sub tema 1.3: Teknologi robot} membantu perawatan pasien

Partisipan menjelaskan bahwa teknologi robot juga dapat memberikan efek positif bagi pasien. Efek positif penggunaan teknologi robot bagi pasien 
yaitu dapat membantu perawatan pasien di ruang ruang perawatan intensif menjadi lebih efektif. Partisipan menjelaskan sebaga berikut:

"Teknologi robot yang digunakan untuk memonitoring kondisi pasien, sehingga pengawasan kondisi pasien akan lebih intensif akan sangat membantu dalam perawatan." (N4)

\section{Tema 2: Efek negatif penggunaan teknologi robot di ruang ruang perawatan intensif}

Pengaplikasian teknologi robot di ruang ruang perawatan intensif selain memiliki efek positif terdapat juga efek negatif dari penggunaannya. Partisipan menjelaskan bahwa sama halnya dengan efek positif, efek negatif penggunaan teknologi robot bisa kepada perawat dan pasien.

Subtema 2.1: Caring perawat ke pasien menjadi berkurang

Partisipan menjelaskan bahwa dalam perawatan kepada pasien di ruang ruang perawatan intensif tetap memperhatikan adanya caring dengan melakukan interaksi, mengajak berkomunikasi dan memberikan perawatan dengan kasih sayang kepada pasien meskipun pasien dalam kondisi tidak sadar. Penggunaan teknologi robot untuk membantu dalam perawatan pasien bisa mengurangi interaksi yang dilakukan oleh perawat kepada pasien. Partisipan menjelaskan sebagai berikut:

"jika robot digunakan untuk melakukan tindakan ke pasien bisa jadi caring perawat kepada pasien akan berkurang, karena semakin sedikit perawat melakukan tindakan ke pasien maka semakin sedikit perawat melakukan interaksi dengan pasien." (N2)

\section{Sub tema 2.2 Menimbulkan kecemasan pada pasien}

Partisipan menjelaskan mengenai efek negatif penggunaan teknologi robot yang bisa dirasakan oleh pasien di ruang ruang perawatan intensif. Pasien dapat merasakan kecemasan ketika berdekatan dengan teknologi robot karena tidak semua pasien di ruang ruang perawatan intensif merupakan pasien tidak sadar tetapi ada pasien yang sadar dan masih bisa berkomunikasi. Partisipan menjelaskan sebagai berikut:

"Penggunaan teknologi robot untuk tindakan ke pasien bisa menyebabkan pasien menjadi cemas. Pasien yang sadar di ruangan akan merasa tidak nyaman ketika ditemani atau dilakukan tindakan oleh robot." (N6)

Sub tema 2.3 Pengoperasian teknologi robot menjadi kendala

Partisipan menjelaskan bahwa penggunaan teknologi robot di ruang ruang perawatan intensif memiliki kendala yang harus ditangani. Kendala yang dihadapi perawat yaitu belum memahami mengenai cara pengoperasian teknologi robot. Sehingga ketika dalam penggunaan teknologi robot, perawat tidak mampu mengoperasikan akan menjadi masalah seperti pekerjaan yang tidak segera selesai. Partisipan menjelaskan sebagai berikut:

“...untuk pengoperasian robot bisa menjadi masalah, meskipun peralatan canggih tetap harus mengetahui cara penggunaannya. Ketika perawat belum mengetahui, dan harus segera melakukan tindakan tetapi terkendala pada pengoperasian robot itu akan membutuhkan waktu yang lama dan menjadi masalah." (N9)

\section{Tema 3: Kebutuhan perawat terkait pengoperasian teknologi robot di ruang ruang perawatan intensif}

Keberadaan teknologi robot untuk membantu pekerjaan perawat di ruang ruang perawatan intensif tentu membutuhkan persiapan untuk penggunaannya. . Partisipan menjelaskan bahwa teknologi robot merupakan hal yang baru sehingga membutuhkan perencanaan 
dan persiapan seperti sosialisasi dan pelatihan kepada perawat ruang perawatan intensif dan petugas lainnya.

\section{Sub tema 3.1 Sosialisasi penggunaan teknologi robot di ruang ruang perawatan intensif}

Partisipan menjelaskan bahwa sosialisasi merupakan hal yang harus dipersiapkan dengan adanya teknologi robot. Hal tersebut karena teknologi robot merupakan hal yang baru dan tidak semua perawat memahaminya, sehingga perlu adanya pengenalan dan peningkatan pengetahuan kegunaan dari teknologi robot yang digunakan. Partisipan menjelaskan sebagai berikut:

"Hal yang perlu dipersiapkan dengan adanya teknologi robot adalah sosialisasi kepada perawat dan petugas rumah sakit. Perlu pengenalan mengenai prosedur yang harus dilakukan untuk penggunaan robot tersebut, jadi dalam penggunaannya nanti tidak akan menjadi kendala." (N1)

\section{Sub tema 3.2 Pelatihan pengoperasian} teknologi robot di ruang ruang perawatan intensif

Partisipan menjelaskan mengenai perlu adanya pelatihan terkait cara pengoperasian teknologi robot yang akan digunakan di ruang ruang perawatan intensif. Pelatihan sangat diperlukan untuk meningkatkan kemampuan perawat dan petugas kesehatan lainnya agar dalam pelaksanaan penggunaan teknologi robot dapat berjalan dengan efektif. Partisipan menjelaskan sebagai berikut:

“...pelatihan mengenai pengoperasian teknologi robot diperlukan. Robot yang secanggih apapun perlu dikontrol dan digunakan sesuai dengan fungsinya robot dalam perawatan." (N9)

\section{Pembahasan}

Penggunaan teknologi robot memberikan efek positif bagi perawat maupun bagi pasien di ruangan. Hasil penelitian menunjukkan bahwa penggunaan teknologi robot dapat membantu pekerjaan perawat, sehingga beban kerja perawat akan berkurang. Hasil ini didukung dengan penelitian mengenai perspektif perawat dalam penggunaan teknologi robot yang menjelaskan bahwa robot dapat membantu perawat dalam hal melakukan pekerjaan sehingga akan mengurangi beban kerja dari perawat (Liang et al., 2019). Penelitian lain menunjukkan bahwa penggunaan teknologi robot sangat memberikan keuntungan bagi perawat untuk membantu pekerjaan yang rutin dikerjakan (Lavazzo \& Gkegkes, 2015). Efek positif penggunaan teknologi robot lainnya yaitu robot bekerja sesuai dengan program. Pada hasil penelitian ini, partisipan menjelaskan dengan adanya penggunaan teknologi robot diharapkan akan membantu dalam hal mengurangi kesalahan karena teknologi robot dirancang sesuai dengan program yang mampu bekerja secara maksimal dalam pekerjaan. Hasil penelitian tersebut didukung dengan penelitian lain bahwa teknologi robot diciptakan dengan memasukkan perangkat cerdas ideal sesuai programmnya dan mampu melakukan pekerjaan secara berulang serta memiliki presisi yang tepat sehingga meminimalkan terjadinya kesalahan (Best et al., 2014). Teknologi robot juga memberikan efek positif bagi pasien yaitu dapat membantu perawatan pasien di ruangan. Hasil penelitian ini didukung oleh penelitian yang menunjukkan bahwa pemanfaatan teknologi robot dapat membantu dalam meningkatkan perkembangan kondisi pasien (Ricks \& Colton, 2010). Hal yang perlu diperhatikan adalah meskipun teknologi robot memiliki efek positif dari penggunaannya, sangat penting bagi perawat untuk tetap memastikan bahwa implementasi dan penggunaan teknologi robot selaras dengan nilai-nilai keperawatan (Archibald \& Barnard, 2018).

Hasil penelitian ini menjelaskan bahwa penggunaan teknologi robot tidak hanya 
memberikan efek positif, tetapi juga terdapat efek negatif. Diantaranya yaitu caring perawat ke pasien menjadi berkurang. Partisipan menjelaskan bahwa penggunaan teknologi ke pasien dapat mengurangi interaksi perawat ke pasien sehingga caring akan menjadi semakin jauh. Hasil ini didukung oleh penelitian yang menjelaskan bahwa penerapan robot ke pasien dapat mengurangi interaksi dan komunikasi yang biasanya dilakukan oleh perawat kepada pasien (Liang et al, 2019).

Penelitian lain menjelaskan bahwa kemungkinan besar akan terjadi adanya penurunan kualitas asuhan keperawatan yang diberikan kepada pasien yaitu terjadi penurunan interaksi dan komunikasi antara perawat dan pasien (Shahpori et al, 2011). Hasil penelitian menunjukkan bahwa selain caring perawat ke pasien menjadi jauh, efek negatif penggunaan teknologi robot dapat membuat pasien merasakan kecemasan dan ketakutan. Hasil ini didukung dengan penelitian yang menjelaskan bahwa pengaplikasian teknologi robot untuk membantu dalam perawatan pasien bisa menimbulkan ketidaknyaman pada pasien (Murray, 2014). Efek negatif lainnya dari penggunaan teknologi robot adalah pengoperasian robot yang menjadi kendala. Kendala yang dihadapi perawat yaitu belum memahami mengenai cara pengoperasian teknologi robot. Sehingga ketika dalam penggunaan teknologi robot, perawat tidak mampu mengoperasikan akan menjadi masalah seperti pekerjaan yang tidak segera selesai. Hasil ini didukung oleh penelitian yang menjelaskan bahwa perawat bisa terkendala dalam pengoperasian teknologi robot, karena meskipun teknologi robot adalah teknologi yang canggih dan otomatis tetap memiliki prosedur dalam penggunaannya. Perawat perlu memahami cara penggunaannya agar tidak menjadi kendala (Liang et al., 2019).

Penelitian lain menjelaskan bahwa dengan adanya penggunaan teknologi robot dalam keperawatan, perawat harus mampu menyesuaikan diri dengan penggunaan teknologi robot tetapi bukan berarti bahwa robot mengambil alih tugas dan kewajiban dari perawat karena fungsi dari teknologi robot adalah sebatas untuk membantu perawat bukan untuk menggantikan atau mengambil alih tugas perawat (Pepito \& Locsin, 2018). Selain itu, penting untuk membuat pedoman etika yang jelas terkait penggunaan robot secara efektif dan pengembangannya dengan mempertimbangkan perawat dan juga pasien (Archibald \& Barnard, 2018).

Hasil penelitian menunjukkan bahwa petugas rumah sakit khususnya perawat perlu memahami terlebih dahulu mengenai penggunaan teknologi robot melalui sosialisasi. Partisipan menjelaskan bahwa sosialisasi sangat dibutuhkan sebagai pengenalan dan untuk peningkatan pengetahuan mengenai kegunaan dari teknologi robot yang akan digunakan. Hasil penelitian ini didukung penelitian yang telah dilakukan yang menjelaskan bahwa pembelajaran pada teknologi baru merupakan hal yang sangat penting bagi penyedia layanan kesehatan untuk keamanan pasien (Bagherian et al., 2017). Pengadaan pelatihan terkait pengoperasian teknologi robot juga merupakan hal yang penting untuk dilakukan. Pembelajaran secara langsung sangat dibutuhkan bagi perawat dan para petugas kesehatan lainnya agar ketika melakukan pekerjaan dengan mengaplikasikan robot tersebut, perawat tidak akan mengalami kendala sehingga pekerjaan akan lebih efektif. Hasil tersebut didukung dengan penelitian lain yang menjelaskan bahwa dibutuhkan pengenalan dan pelatihan pada teknologi robot yang canggih karena teknologi robot akan berperan penting dalam pekerjaan perawat dan juga membantu dalam perawatan pasien (Raheem et al., 2017).

\section{Simpulan}

Hasil penelitian menjelaskan bahwa penggunaan teknologi robot di keperawatan memiliki efek positif dan negatif dalam pelaksanaannya. Efek positif diantaranya 
yaitu teknologi robot dapat membantu pekerjaan perawat, teknologi robot membantu perawatan pasien dan teknologi robot bekerja sesuai dengan program. Selain efek positif, teknologi robot juga memiliki efek negatif diantaranya adalah caring perawat kepada pasien dapat berkurang, teknologi robot dapat menimbulkan kecemasan pada pasien, dan pengoperasian teknologi robot yang menjadi kendala. Penerapan teknologi robot di rumah sakit dan di ruangan perlu mendapatkan sosialisasi dan pelatihan sebagai pengenalan dan untuk meningkatkan keterampilan dalam pengoperasian teknologi robot kepada petugas kesehatan khususnya perawat agar perawat mampu bekerja secara efektif dengan melibatkan penggunaan teknologi robot. Hal yang perlu diperhatikan adalah meskipun teknologi robot memiliki efek positif dari penggunaannya, sangat penting bagi perawat untuk tetap memastikan bahwa implementasi dan penggunaan teknologi robot selaras dengan nilai-nilai keperawatan. Teknologi robot apabila diterapkan di rumah sakit, maka perawat perlu menyesuaikan diri dan perawat tetap perlu memastikan bahwa implementasi dan penggunaan teknologi robot selaras dengan nilai-nilai keperawatan untuk membantu dalam perawatan pasien.

\section{Persantunan}

Peneliti mengucapkan terimakasih kepada semua pihak yang telah membantu penelitian ini dari awal hingga akhir.

\section{Daftar Pustaka}

Archibald, M. M., \& Barnard, A. (2018). Futurism in nursing: technology, robotics and the fundamentals of care. Journal of Clinical Nursing, 27(11-12), 2473-2480.

Bagherian B, Sabzevari S, Mirzaei T, Ravary A (2017). Meaning of Caring from Critical Care Nurses" Perspective: A Phenomenological
Study. Journal of Intensive Critical Care, 3(3), 1-9.

Best, J., Day, L., Ingram, L., Musgrave, B., Rushing, H., \& Schooley, B. (2014). Comparison of Robotic vs. Standard Surgical Procedure on Postoperative Nursing Care of Women Undergoing Total Abdominal Hysterectomy. Medical Surgical Nursing, 23(6).

Darmayanti, N. N. T., \& Oktamianti, P. (2014). Analisis Kompetensi Perawat Ruang Intensif (Ruang perawatan intensif) Rumah Sakit Umum Tabanan Tahun 2013. Jurnal Sistem Informasi MTI-UI, 1(1), 77-104.

Khunlertkit, A., \& Carayon, P. (2013). Contributions of tele-ruang perawatan intensif (Tele-ICU) technology to quality of care and patient safety. Journal of Critical Care, 28(3), 315-e1.

Lavazzo, C., \& Gkegkes, I. D. (2015). Enhanced recovery programme in robotic hysterectomy. British Journal of Nursing, 24(Sup16), S4-S8.

Liang, H. F., Wu, K. M., Weng, C. H., \& Hsieh, H. W. (2019). Nurses' Views on the Potential Use of Robots in the Pediatric Unit. Journal of pediatric nursing, 47, e58-e64.

Murray, C., Ortiz, E., \& Kubin, C. (2014). Application of a robot for critical care rounding in small rural hospitals. Critical Care Nursing Clinics, 26(4), 477-485.

Pepito, J. A., \& Locsin, R. (2019). Can nurses remain relevant in a technologically advanced future?. International journal of nursing sciences, 6(1), 106-110.

Raheem, A. A., Song, H. J., Chang, K. D., Choi, Y. D., \& Rha, K. H. (2017). Robotic nurse duties in the urology operative room: 11 years of experience. Asian journal of urology, 4(2), 116-123.

Ricks, D. J., \& Colton, M. B. (2010, May). Trends and considerations in robot- 
assisted autism therapy. In 2010 IEEE international conference on robotics and automation (pp. 43544359). IEEE.

Shahpori R, Hebert M, Kushniruk A, Zuege D. (2011). Telemedicine in the ruang perawatan intensif environment-A survey of the attitudes and perspectives of critical care clinicians. Journal of Critical Care,
26(3), 328.e9-328.e15.

Tanioka, T., Osaka, K., Locsin, R., Yasuhara, Y., \& Ito, H. (2017). Recommended design and direction of development for humanoid nursing robots perspective from nursing researchers. Intelligent Control and Automation, 8(2), 96110. 